\title{
Milliliter per Microgram per Kilogram
}

National Cancer Institute

\section{Source}

National Cancer Institute. Milliliter per Microgram per Kilogram. NCI Thesaurus. Code C120822.

A unit of concentration equal to milliliter divided by microgram per kilogram. 